

\title{
EVALUATION OF THE BEIJING INSTRUMENT FACTORY GDB-52LD PHOTOMULTIPLIER
}

\author{
Eric Young and C.C. Lo
}

\author{
Electronics Research and Development Group \\ Department of Instrument Science and Engineering \\ Lawrence Berkeley Laboratory \\ University of Cal ifornia \\ Berkeley, CA 94720
}

December 15, 1982

\section{DISCLAIMER}

\begin{abstract}
This report was prepared as an account of work sponsored by an agency of ihe United States Government. Neither the Unitred States Government nor any agency thereof, nor any of thejr cmployees, makes any warranity, express or implied, or assumes any legal liability or resporsibility for the accuracy, completeness, or usefulness of any information, apparatus, product, or process disclosed, or fepresents that its use would not infringe privately owned rights. Reference herein to any specilic commercial froduct, process, or service by trade name, trademark. manufacturer, of otherwise does not necessatily constitute or imply its endorsement, recommendation, or favoring by the United States Government or any agency thereof. The views and opjnions of authors expressed herein do not necessarily state or reflect those of the United States Government or any agency thereof.
\end{abstract}

This work was performed as part of the progran of the Electronics Research and Development Group of the Lawrence Berkeley Laboratory and was partially supporPhysics, Division of High Energy Physics of the U. S. Department of Energy under Contract No. DE-ACD3-76SF00098. 


\section{EVALUATION OF THE BEIJING INSTRUMENT FACTORY \\ GDB-52LD PHOTOMULTIPLIER}

Eric Young and C.C. Lo

Electronics Research and Development Group

Department of Instrument Science and Engineering

Lawrence Berkeley Laboratory

University of Cal ifornia

Berkeley, California 94720

\section{Abstract}

Characteristics have been measured for the G08-52LD 2"-diameter photomultiplier. Some typical photomultiplier characteristics -- such as gain, dark current, anode output current, transit and rise times as a function of voltage between anode and cathode, and photoelectron pulse-height spectrum, the quantum-efficiency, and the single-electron transit time spread were measured. Descriptions of the measuring systems were also given.

\section{Introduction}

The GDB-52LD is a $5 \mathrm{~cm}$ diameter, flat face, ten stage, head on photomiltiplier tube using a venetian blind type multiplier system. This tube has a bialkaline photocathode. The GDB-52LD phctomultipliers are manuf actured oy the Beijing Comprehensive Instrument Factory.* A photograph of the GDB-52LD photomultiplier is shown in Fig. 1.

*Full addresss: China Nuc lear Inergy Industry Corporation (Beijing Comprehensive Instrument Factory) P.0. Box 2139 , Beijing, China (P.R.C.) 
Gain and Dark-Current Measurements

The voltage divider, shown in Fig. 2, was used in measuring the gain and dark current. A block diagram of the system for the gain measurements is shown in Fig. 4. The light source was a 1859 lamp driven by a $40-\mathrm{Hz}$ squarewave generator. The dark current as a function of voltage between the cathode and anode was measured. The gain and dark-current characteristics of the multiplier as a function of the voltage applied between cathode and anode are shown in Fig. 5.

\section{Anode Output Pulse Current}

The output pulse current performance depends on the voltage divider used and the applied voltage. The measurements of the output pulse current were made with the system shown as a block diagram in Fig. 6 . The mercury light. pulser, described 11 the LRL Counting Hanubook CC8-30, was used as the light source. Using MELI.ES-GRIOT fused silica neutral density filters as light attenuators, the anode output pulse current as a function of light intensicy was measured and plotted in Fig. 7. The intensity of the pulsed light source was kept constant during the measurement. The voltage divider shown in Fig. 3 was used for this measurentent and all other measurements which follow.

\section{Electron Transit Time}

The electron transit time was measured by means of the system shown in Fig. 8. The electrical signal from the mercury light source was used as the reference pulse. The transit time was measured from $50_{w}^{m}$ of the leading-edge 
amplitude of the reference pulse to $50 \%$ of the leading-edge amplitude of the photomultiplier output pulse. The results of the measurements are given in Fig. 9.

\section{Anode-Pulse Rise Time}

The measurement of the anode-puise rise time was made by means of the system shown in Fig. 8. The output current pulse was chosen to be in the linear region of the anods output current characteristics at the various voltage settings between the anode and $c$ athode. The results of the measurement are shown :: Fig. 10 .

\section{Single Electron Time Spread}

A block diagram of the system used to measure single electron time spread is shown in Fig. 11. The measurement was made with the photoc athode fully illuminated. The time distribution shown in Fig. 12 was found to be $18.5 n s$ at FWHM.

\section{Pulse-He ight Resolution}

The pulse-height resolution capabilities of the photomultiplier are signii icant for the detection and measurement of very low-light level scintillations in which only a few electrons are produced. High resolution permits the elimination of almost all single-electron dark pulses from the low-level scintillations. 1,2 
The pulse-height resolution of the GDB-52LD was measured by means of the system whose block diagram is shown in Fig. 13. A light-emitting oiode driven by a pulse generator was used as the light-pulse generator. The pulse-height spectrum is shown in Fig. 14.

\section{Quantum Efficiency}

Quantum efficiency was measured by comparing the GOB-52LD with a calibrated RCA8850 PM Tube. QE was found to be $19.2 \%$ for one tube (5N10-3A) and $16.2 \%$ for the other tube (SN10-8A) at. $410 \mathrm{~nm}$.

\section{Acknowledgment}

This work was perfomed as part of the program of the Electronics Research and Development Group of the Lawrence Berkeley Laboratory and was partially supported by the Director, Office of Energy Research, Office of High Energy Nuclear Physics, Division of High Energy Physics of the U. S. Dejartinent of Energy under Contract No. DE-AC03-76SF00098.

The authors would like to express their appreciation to the China Nuclear Energy Industry Corporation (Beijing Comprehensive Instrument Factory) for the loan of the photomu?tipliers.

Reference to a company or product name does not imply approval or recommendation of the product by the University of California or the U. S. Department of Energy to the exclusion of others tirat may be sijitable. 


\section{Reference 5}

1. C. C. Lo and B. Leskovar, Evaluation of the 8850 Photomultiplier with a Cesiated Gallium-Phosphide First Dynode, Lawrence Berkeley Laboratory, Engineering Note No. 1383, September 1971, University of California, Berkeley, Cal ifornia.

2. B. Leskovar and C. C. Lo, Perfomance Studies of Photomultipliers having Dynodes with GaP(CS) Secondary Emitting Surface, IEEE Transaction Nuc 1. Sci., NS-19, No. 3, 60-72 (1972).

3. C. C. Lo and B. Leskovar, A Measuring System for Studying the Time Resolution Capabilities of Fast Photomultipliers, IEEE Transaction Nuc l. Sci. NS-21 No. 1, 93-105 (1974).

\section{Figure Captions}

Fig. 1. The GDB-52LD photomultiplier tube.

Fig. 2. Schematic diagram of high gain divider.

Fig. 3. Schematic diagram of high current divider.

Fig. 4. Block diagram of the system for gain measurement.

Fig. 5. Gain and dark current as a function of voltage between anode and cathode.

Fig. 6. Block diagram of the system for anode output pulse current mea surement.

Fig. 7. Anode output gulse current as a function of light transmission of the optical attenuator.

Fig. 8. Block diagram of the system for transit-time and rise-time measurement.

Fig. 9. Transit time as a function of voltage oetween anode and cathode.

Fig. 10. Anode pulse rise time as a function of voltage between anode and c athode.

Fig. 11. Block diagram of the system for single electron time spread mea surement $\mathrm{s}$.

Fig. 12. Single electron time spread, full photocathode illuminated.

Fig. 13. Block diagram of the system for pulse-height resolution measurements.

Fig. 14. Pulse-height resolution response. 


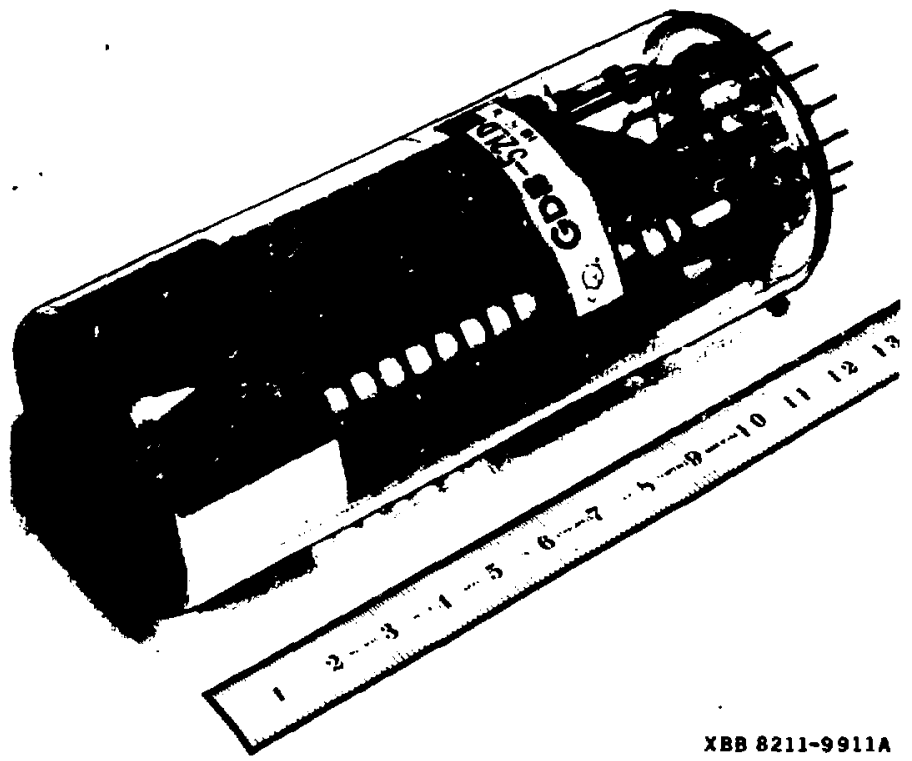

Fig. I. The GDB-52LD photomultiplier tube. 


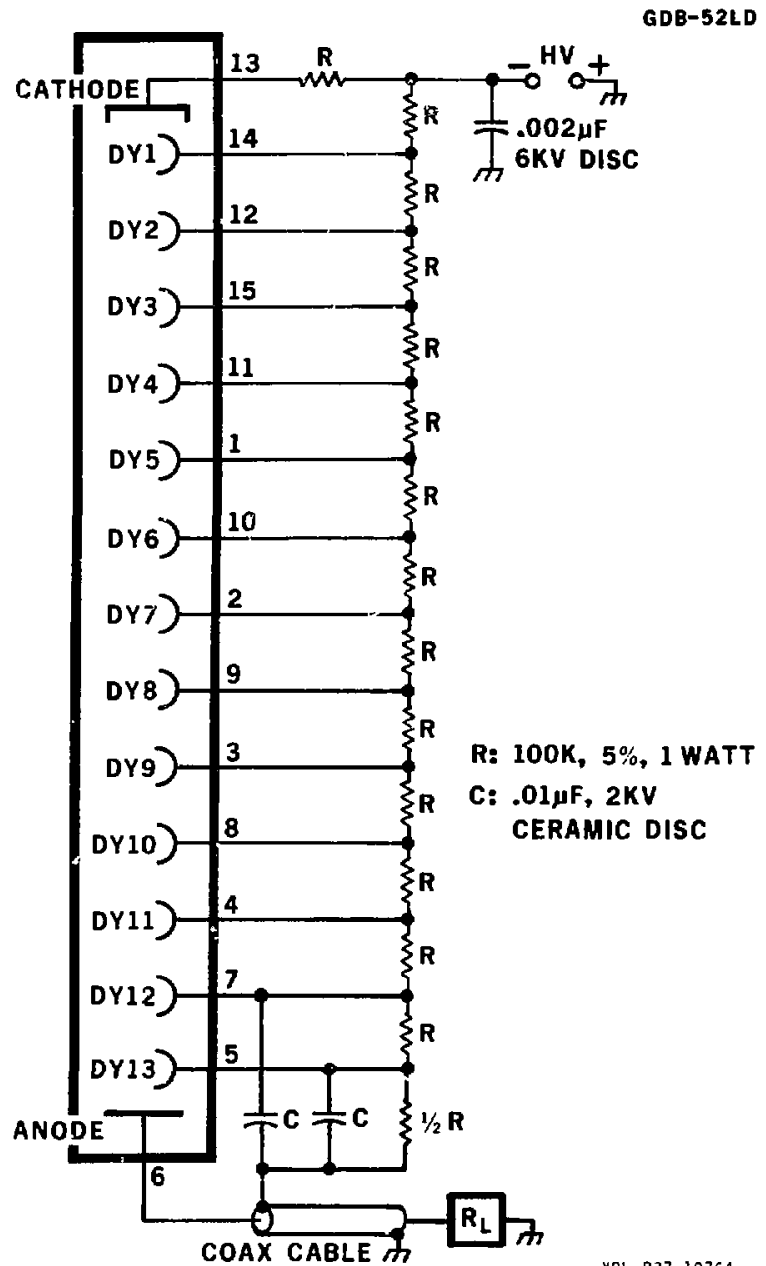

XBL B37-10764

Fig. 2. Schematic diagram of high gain divider. 


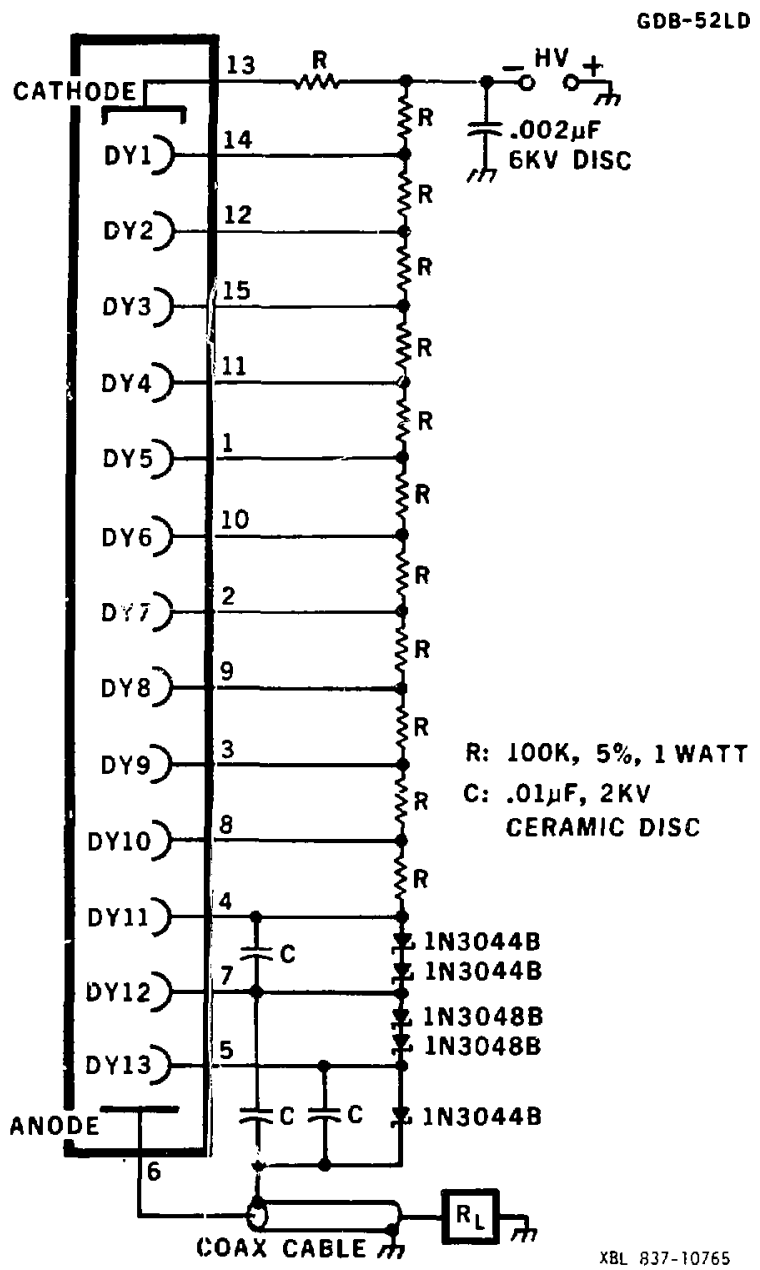

Fig. 3. Schematic diagram of high current divider. 


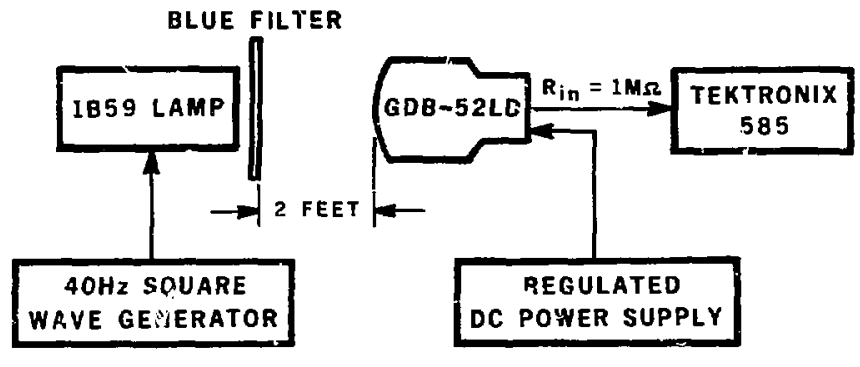

XBL $837-10766$

Fig. 4. Block diagram of the system ior gain measurement. 


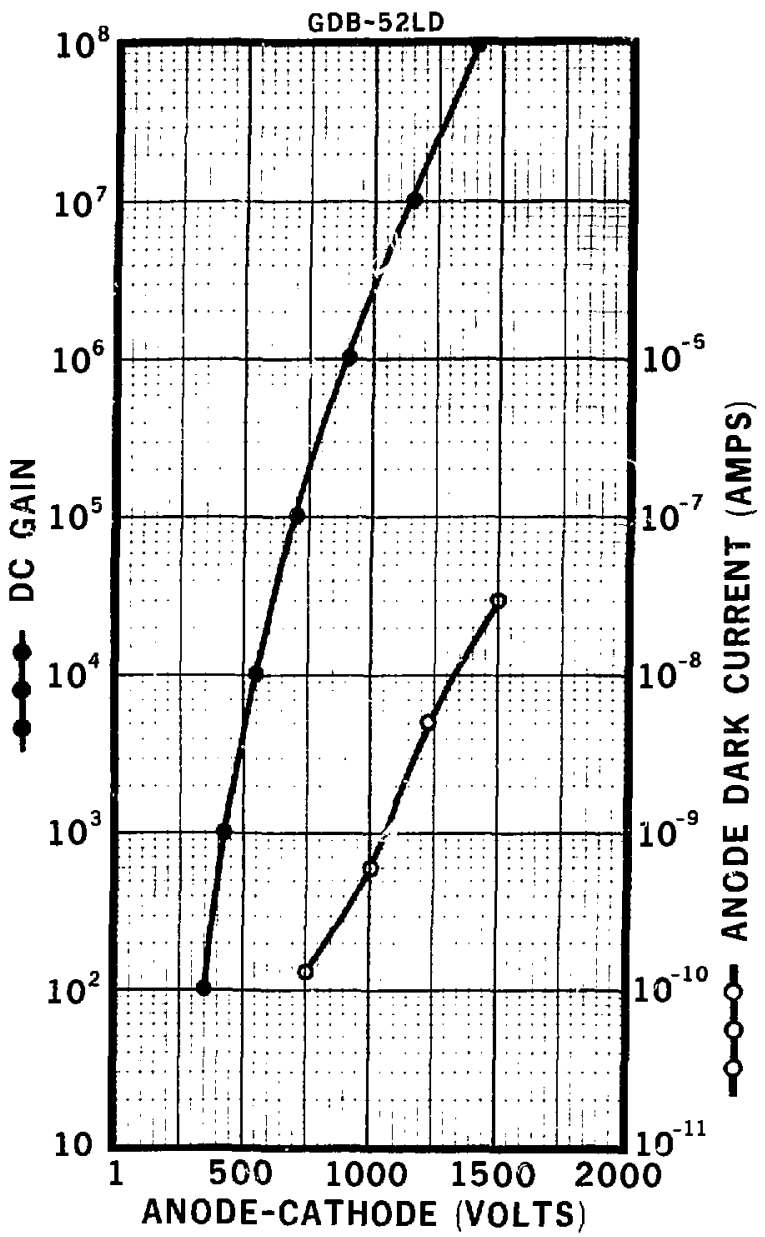

$X B L \quad 837-10767$

Fig. 5. Gain and dark current as a function of ltage between anode and cathode. 


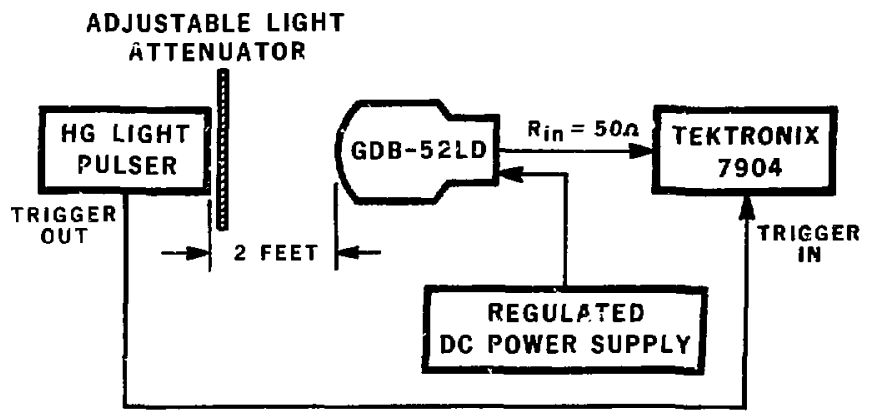

XBL 837-10768

Fig. 6. Block diagram of the system for anode output pulse current measurement. 


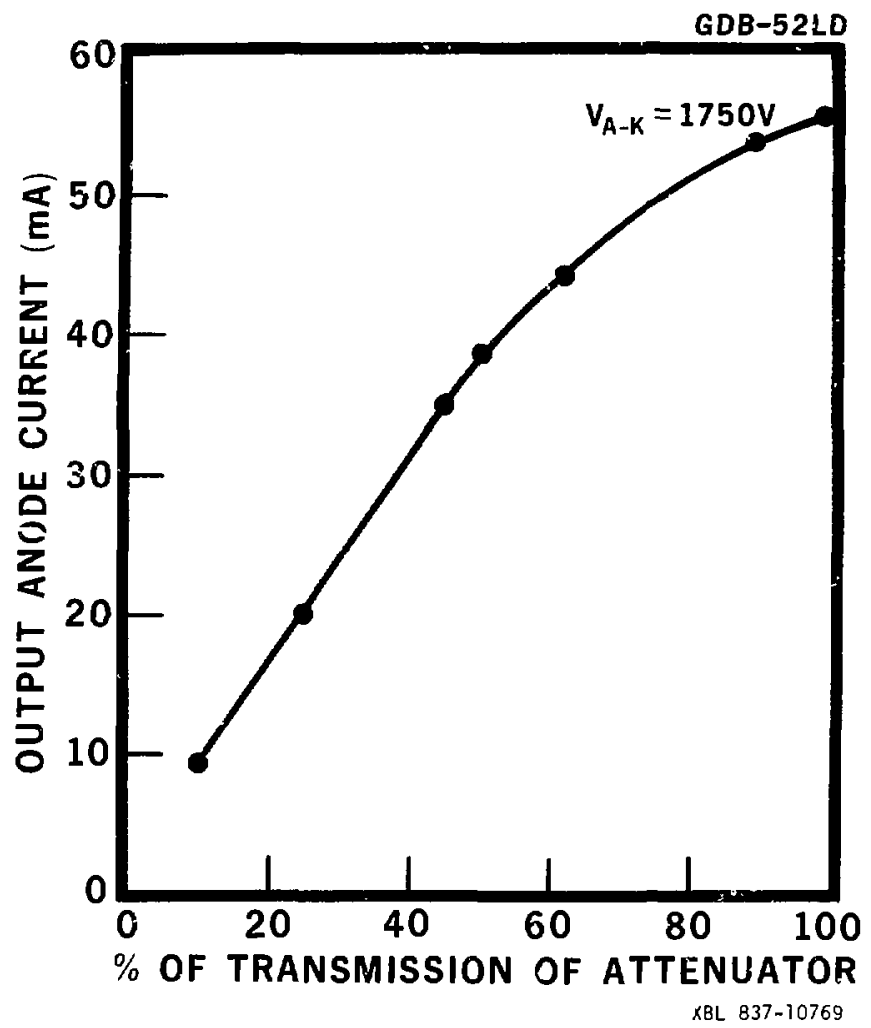

Fig. 7. Anode output pulse current as a function of light transmission of the optical attenuator. 


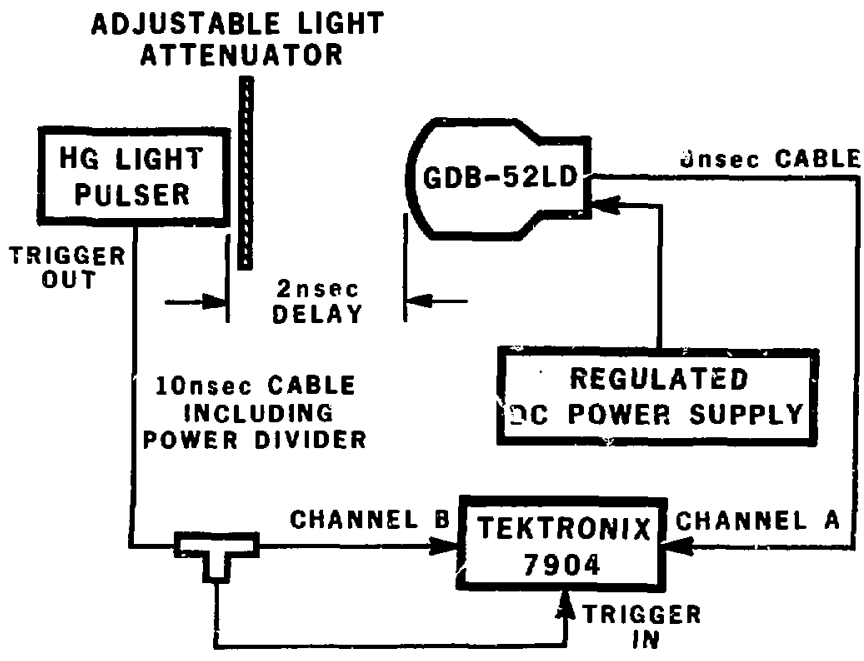

XBL $837-10770$

Fig. 8. Block diagram of the system for transit-time and rise-time measurement. 


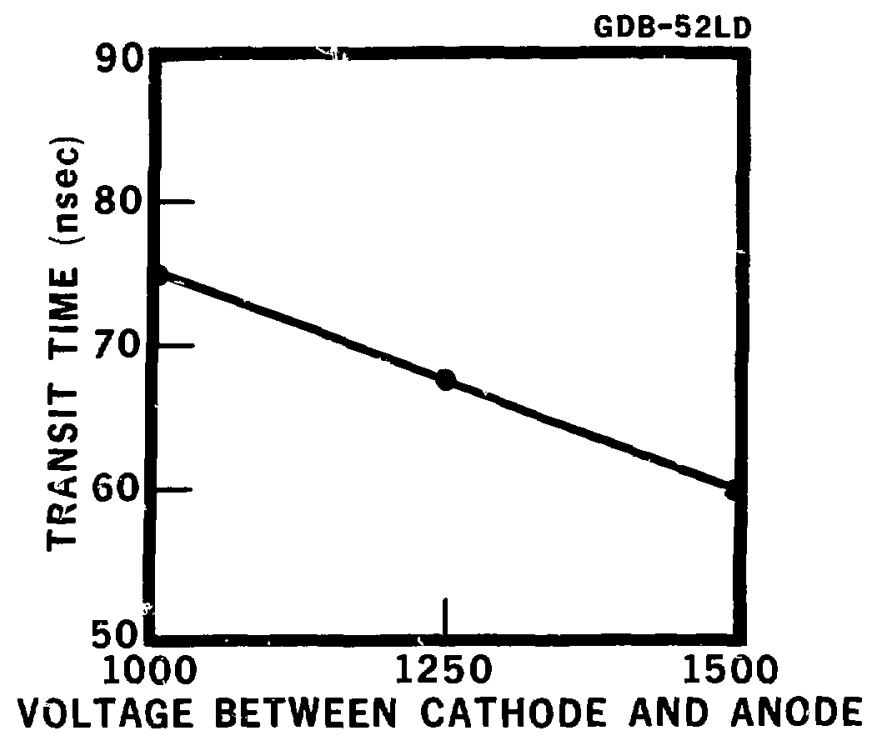

XBL $837-10771$

Fig. 9. Transit time as a function of inltage between anode and cathode. 


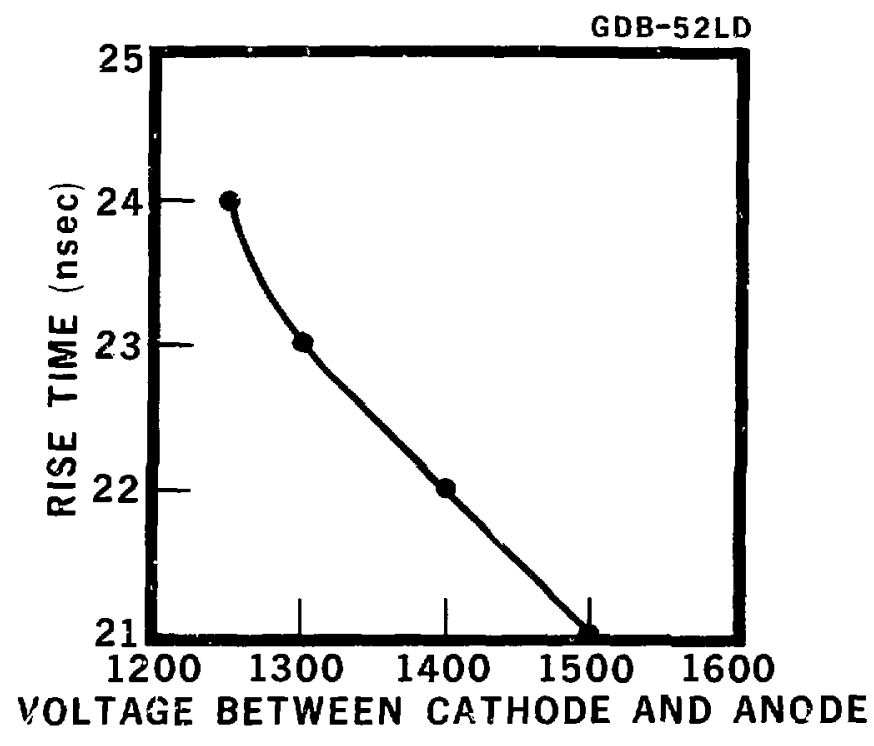

XEL $837-10772$

Fig. 10. Anode pulse rise time as a function of voltage between anode and cathode. 


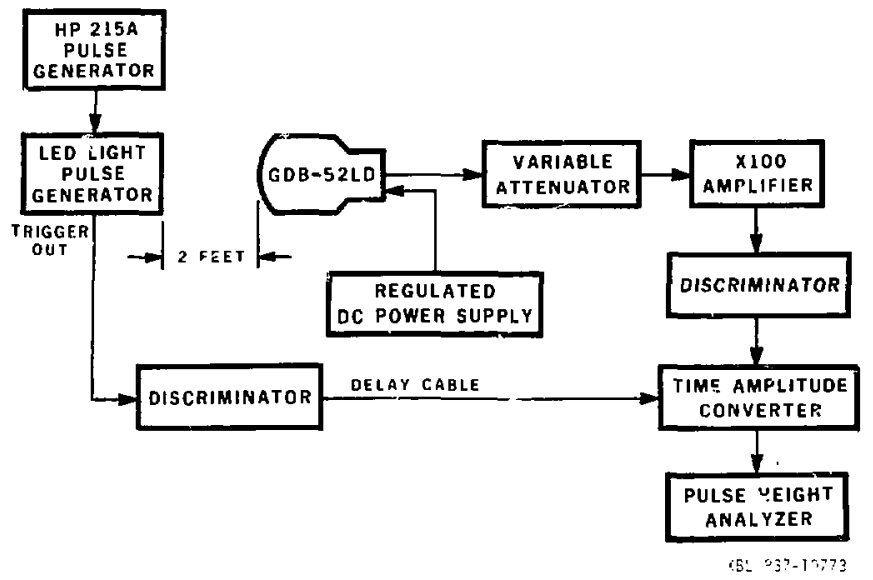

Fig. 11. Block diagram of the system for single electron time spread measurement $s$. 


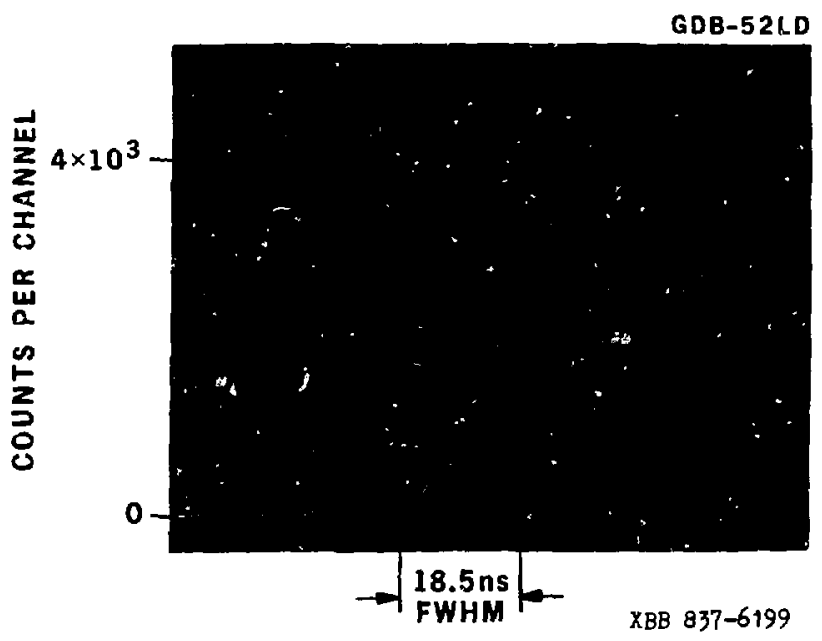

Fig. 12. Single electron time spread, full photocathode j) Iumina ted. 


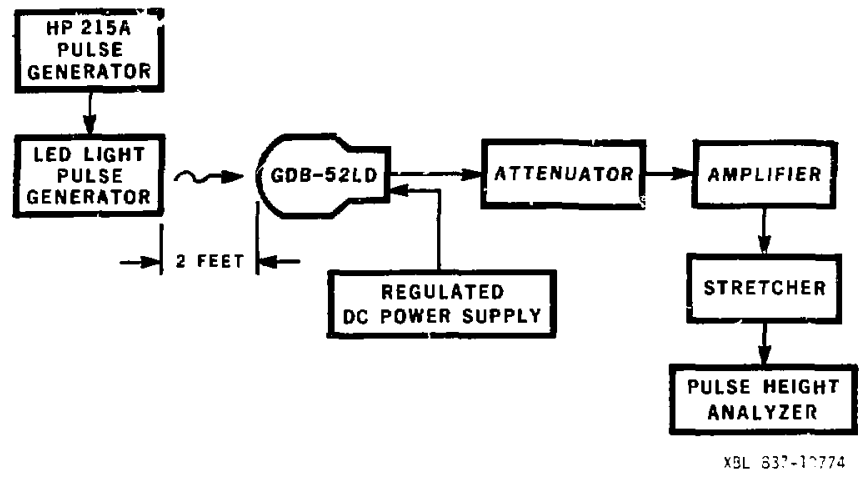

Fig. 13. Block diagram of the system for pulse-height resolution measurements. 


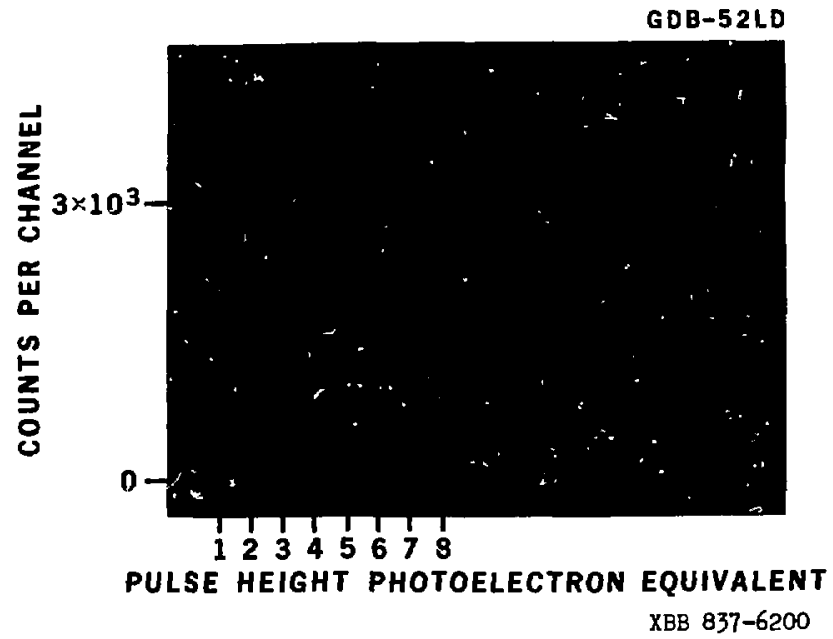

Fig. 14. Pulse-height resolution response. 
This report was done with suppor from the Department of Energy. Any conclusions or opinions expressed in this report represent solely those of the author(s) and not neecssarily those of The Regents of the University of California, the Lawrence Berkeley Laboratory or the Department of Energy.

Reference to a company or product name docs not imply approval or recommendation of the producl by the Universily of Culifornia or the U.S. Department of Energy to the exclusion of others that may be suitable. 